\title{
Direct Phase Digital Control Method in Power Inverters Based on Dumping Frequency Analysis
}

\author{
Ljupco Karadzinov \\ Faculty of Electrical Engineering and IT \\ Sts. Cyril and Methodius University \\ Skopje, Republic of Macedonia \\ 1.karadzinov@feit.ukim.edu.mk
}

\author{
Goce Stefanov \\ Faculty of Electrical Engineering \\ University Goce Delcev \\ Stip, Republic of Macedonia \\ goce.stefanov@ugd.edu.mk
}

\begin{abstract}
Direct phase or indirect frequency control methods are used in series-resonant bridge power inverters for induction heating to maintain maximum power transfer as the load equivalent electrical parameters change during the heating process. The paper present mathematical analysis of the output voltage and current phase angle dependence on the resonant circuit dumping frequency when it is excited with pulse voltage with a different frequency than the resonant one. Based on this analysis and using only measurements of the deviation of the phase angle from its reference value, an improved control method is derived that calculates the new bridge switching frequency. An algorithm for digital implementation is presented. The improved method is verified by simulations and experiments on a prototype.
\end{abstract}

Keywords-series-resonant bridge inverter; direct phase control method; digital control algorithm; dumping frequency.

\section{INTRODUCTION}

Series-resonant bridge inverters are used in a variety of applications. Maximum energy is transferred to the load when the converter switching frequency is same to the resonant one. In some applications, like direct induction heating, the heated work-piece equivalent electrical parameters are part of the resonant circuit [1-4]. As the temperature of the work-piece is increased, the resonant tank inductance and resistance change, thus changing the circuit resonant frequency. To ensure maximum energy transfer, the inverter control circuitry must adjust the switching frequency so that it follows the change of the resonant frequency. Different control algorithms are used to adjust the switching to the resonant frequency. Several of them are based on direct frequency control [5-6] and other use indirect frequency control by controlling the phase angle $\varphi$ between the inverter output voltage and current [7-15]. The last control type, instead of indirect frequency, is more often called direct phase control method. Phase control provides reliable drive of the resonant converter in the presence of large dynamic changes in the load impedance during star-up, natural tracking of component variations with temperature and time, simplified control to output dynamics and a more linear relationship between phase command and output current when compared to frequency control $[10,11]$.

In the analysis of serial resonant converters it is usual to use the resonant circuit frequency $\omega_{0}$ for two reasons: 1) assuming that the value of the resistance of the resonant tank is very small the dumping is negligible and thus resonant $\omega_{0}$ and damping $\omega_{\mathrm{d}}$ angular frequencies have very close values; 2 ) active power is calculated using the phase angle between voltage and current first harmonics. However, in bridge resonant converters the voltage waveforms are pulse and the current has a dumped sinusoidal form. In such cases the phase angle is calculated in respect to the dumping frequency and derived expressions show qualitatively different behavior. Based on dumping frequency analysis of the dependence of the phase angle $\varphi$ on the switching frequency $\omega_{\mathrm{s}}$ we develop improved direct phase control method and verify its performance with simulations and measurements on a prototype of a fullbridge series resonant inverter for induction heating.

\section{DIRECT PHASE CONTROL METHOD}

Fig. 1 shows a block diagram of the feedback control circuitry used in the direct phase control of full-bridge seriesresonant inverter. It comprises of a current transformer that measures the resonant circuit (output) current, a zero crossing detector that gives zero voltage when $i_{\text {out }}(t)<0$ and positive voltage when $i_{\text {out }}(t)>0$, a microcontroller that implements the control algorithm, optocoupler galvanic isolation, a driver circuit that supplies firing pulses to the IGBT switches and a feedback circuit for IGBT overload protection measuring collectoremitter voltages $v_{\mathrm{CE}}$ to limit currents through $\mathrm{T} 1$ to $\mathrm{T} 4$.

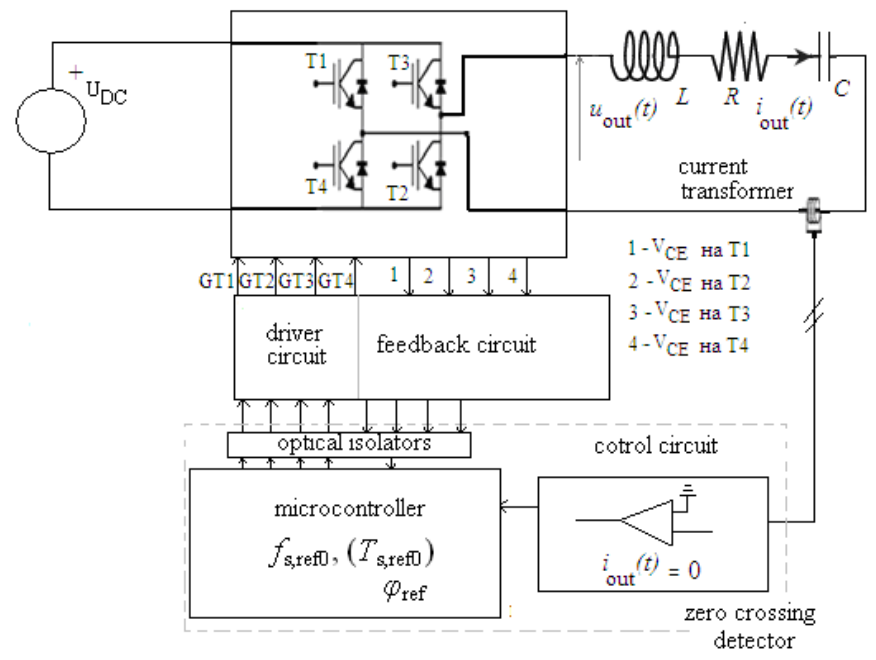

Fig. 1. Block diagram of the full-bridge series-resonant inverter. 
The microcontroller program has predefined values for the initial value of the switching frequency $f_{\mathrm{s} \text {,ref0 }}\left(\right.$ or period $T_{\mathrm{s} \text {,ref0 }}=$ $\left.1 / f_{\mathrm{s}, \mathrm{ref} 0}\right)$ and the desired or the reference phase difference between the output voltage and current $\varphi_{\text {ref. }}$ This phase difference would be zero or close to zero if maximum power transfer is needed, or have a specific value that corresponds to the desired output power when we like to control the power transfer.

Fig. 2 shows the output voltage and current waveforms in the more usual above-resonance mode of operation. In induction heating/melting and similar applications the heated workpiece equivalent electrical parameters are part of the resonant circuit. As the work-piece temperature increases, its equivalent resistance and inductance change, thus changing the circuit resonant frequency. Consequently, the deviation of the switching frequency from the resonant one is also changed, which results in undesired change of output power.

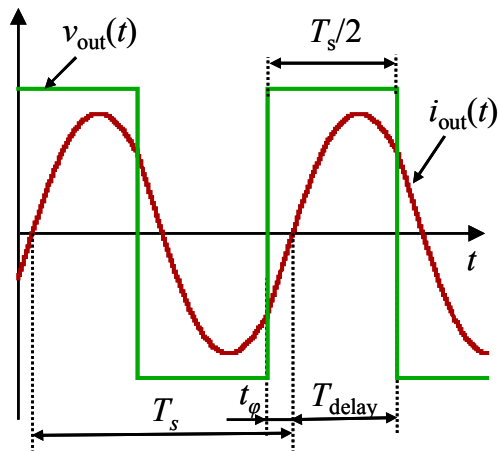

Fig. 2. Output voltage and current waveforms in above-resonance mode.

To maintain the desired output power the switching frequency needs to be adjusted. Control methods $[10,11]$ achieve this by adjusting the interval $T_{\text {delay }}$ (after which T3 and T4 are switched off, and T1 and T2 switched on) according to (1).

$$
T_{\text {delay }}=\frac{T_{s}}{2}-t_{\varphi, \text { ref }}=\frac{T_{s}}{2}-\varphi_{\text {ref }} \frac{T_{s}}{360^{\circ}}
$$

The new values of the positive half-period and consequently the new switching frequency are determined by the desired phase angle which makes this method a direct phase control one. This method has an advantage of being very simple and easy to implement with a low cost microcontroller. However, it has several disadvantages: the period (frequency) adjustments are made only in every positive half-wave; $T_{\text {delay }}$ in (1) and the negative half-period are calculated using the period value $T_{\mathrm{s}}$ of the previous cycle; and as a consequence, the voltage pulses duty ratio is different than 0.5 during the adjustment period. For the phase angle time equivalent $t_{\varphi \text {,ref }}$ calculation in (1) the switching period $T_{\mathrm{s}}$ value is used as is in the analysis where the first harmonics of the output voltage and current are compared. In Fig. 2 the current waveform is comprised of pieces of damped oscillation and $\varphi$ and $t_{\varphi}$ depend on the circuit damping frequency. In order to make improvements to this method we first theoretically analyze the phase angle dependence on the deviation of the switching from the resonant/damping frequency.

\section{PhASE ANGLE DEPENDENCE ANALYSIS}

Analysis of the series-resonant converters usually use the voltage and current first harmonics to determine the circuit parameters and behavior. Assuming that the resistance in the circuit is small, the resonant frequency $\omega_{0}$ is used in the calculations. To show the difference in these two approaches we first review the results with sine-wave voltage exaction and then elaborate the square-pulse excitation case.

\section{A. Sine-wave excitation}

When a series resonant circuit is excited by a sine wave voltage, all waveforms have the same shape and the current phase $\varphi$ in respect to the voltage is a well known relation (2):

$$
\varphi=\operatorname{arctg}\left[Q\left(\frac{\omega_{s}}{\omega_{0}}-\frac{\omega_{0}}{\omega_{s}}\right)\right]
$$

where $\omega_{\mathrm{s}}$ is the switching, $\omega_{0}=1 /(L C)^{1 / 2}$ the resonant angular frequency and the quality factor is $Q=\omega_{0} L / R=1 /\left(\omega_{0} R C\right)$.

The range of values for $Q$ and $\omega_{0}$ can be obtained using the real parameter values of the prototype resonant inverter for induction heating (used for method verification at the end of this paper) with rated power of $10 \mathrm{~kW}: R=0.24 \Omega$, $L=26.5 \mu \mathrm{H}, C=26.6 \mu \mathrm{F}$. Using these parameters' values it is obtained that $\omega_{0}=37664 \mathrm{rad} / \mathrm{s}\left(f_{0}=5994 \mathrm{~Hz}\right)$ and $Q=4.16$. Table I summarizes $\omega_{0}, f_{0}$ and $Q$ values with typical $R$ and $L$ change of $\pm 50 \%$ during metal-piece induction melting. Fig. 3 shows the phase $\varphi$ change dependence on normalized switching frequency $x=\omega_{s} / \omega_{0}$ for three values for $Q=3,4$ and 5 .

TABLE I. RANG OF CHANGE OF $Q$ WITH $R$ AND $L$ CHANGE $\pm 50 \%$

\begin{tabular}{|c|c|c|c|c|c|c|c|c|}
\hline$R(\Omega)$ & $\Delta R / R(\%)$ & $L(\mu \mathrm{H})$ & $\Delta L / L(\%)$ & $\omega_{0}(\mathrm{rad} / \mathrm{s})$ & $f_{0}(\mathrm{~Hz})$ & $Q$ & $\Delta \omega_{0} / \omega_{0}(\%)$ & $\Delta Q / Q(\%)$ \\
\hline 0.12 & -50 & 13.25 & -50 & 53266 & 8477 & 5.88 & +41 & +41 \\
\hline 0.24 & 0 & 26.50 & 0 & 37664 & 5994 & 4.16 & 0 & 0 \\
\hline 0.36 & +50 & 39.75 & +50 & 30753 & 4895 & 3.35 & -18 & -18 \\
\hline
\end{tabular}

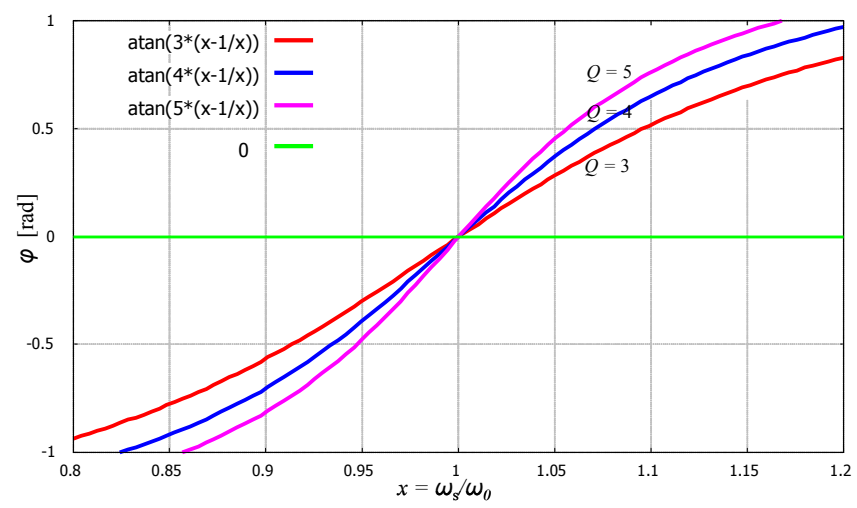

Fig. 3. Phase angle $\varphi$ dependence on $x=\omega_{\mathrm{s}} / \omega_{0}$ for $Q=3,4$ and 5 , when the series resonant circuit is exited by a sinusoidal voltage.

\section{B. Square pulse excitation}

Let us now consider the series-resonant circuit excited by voltage pulses. If the voltage is in form of the Heaviside step function, then the current oscillates around zero with angular dumping frequency $\omega_{\mathrm{d}}$, as shown in Fig. 4 . When the voltage has square pulses waveform (duty ratio $D=0.5$ ) and amplitude $\pm V_{\mathrm{DC}}$, then in every half-period the current is a piece of the dumped oscillation of Fig. 4 and looks like the waveform shown in Fig. 2. In the steady state the negative half-period waveform is symmetrical to the positive one in respect to the 


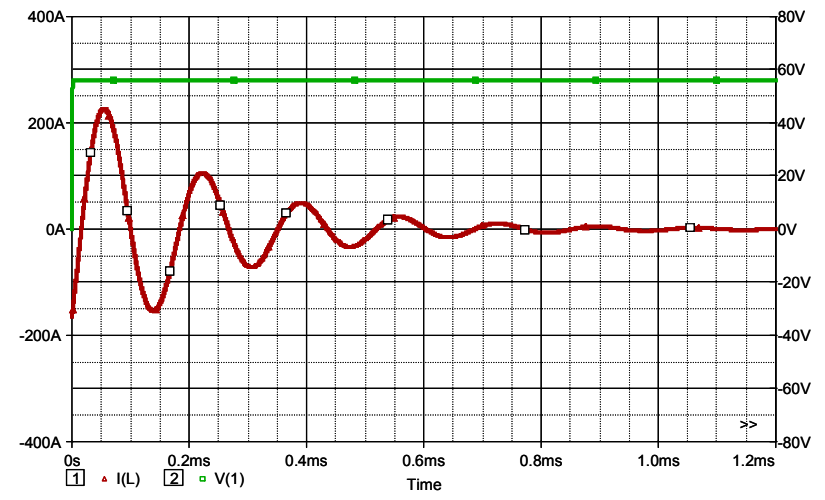

Fig. 4. Current waveform in the series-resonant circuit when excited by a Heaviside step voltage with amplitude $V_{\mathrm{DC}}=56 \mathrm{~V}$. Parameters' values are $R=0.24 \Omega, L=26.5 \mu \mathrm{H}$ and $C=26.6 \mu \mathrm{F}$ with initial values $i_{\mathrm{L}}\left(0^{+}\right)=$ $-165 \mathrm{~A}$ and $u_{\mathrm{C}}\left(0^{+}\right)=-163 \mathrm{~V}$ to match the initial conditions in Fig. 2.

time axis. Harmonic analysis can be done in this case for the calculation of the active and reactive power, power factor etc. However, to determine the $t_{\varphi}$ (and $\varphi$ ) as defined in Fig. 2 and its dependence on the deviation of $\omega_{\mathrm{s}}$ from $\omega_{\mathrm{d}}$, the actual time waveforms from Fig. 4 have to be analyzed. Such analysis has not been carried in the literature to the best of our knowledge.

The series-resonant circuit current waveform for one halfperiod can be obtained from the second-order differential equation (4):

$$
\frac{\mathrm{d}^{2} i(t)}{\mathrm{d} t^{2}}+\frac{R}{L} \frac{\mathrm{d} i(t)}{\mathrm{d} t}+\frac{i(t)}{C L}=\frac{1}{L} \frac{\mathrm{d} v(t)}{\mathrm{d} t}
$$

The solution in this case is the under-dumped one $\left(\alpha<\omega_{0}\right)$ since the current oscillates (Fig.4), it has no DC component since $v(t)$ is constant $(\mathrm{d} v / \mathrm{d} t=0)$ and has the form (4) or (5):

$$
\begin{gathered}
i(t)=e^{-\alpha t}\left(A_{1} \cos \omega_{\mathrm{d}} t+A_{2} \sin \omega_{\mathrm{d}} t\right) \\
i(t)=e^{-\alpha t} K \sin \left(\omega_{\mathrm{d}} t-\varphi\right)
\end{gathered}
$$

where

$$
\begin{gathered}
\alpha=\frac{R}{2 L}=4528 \mathrm{~s}^{-1}, \omega_{0}=\frac{1}{\sqrt{L C}}=37665 \frac{\mathrm{rad}}{\mathrm{s}}, \text { and } \\
\omega_{\mathrm{d}}=\sqrt{\omega_{0}^{2}-\alpha^{2}}=37392 \frac{\mathrm{rad}}{\mathrm{s}}
\end{gathered}
$$

Determination of the two constants $K$ and $\varphi$ for the steadystate solution can be done using two border conditions for this time interval, i.e. $i(0)=-I_{0}$ and $i\left(T_{\mathrm{s}} / 2\right)=+I_{0}$ :

$$
\begin{aligned}
& \text { for } t=0 \\
& \text { for } t=T_{\mathrm{s}} / 2 \quad i(0)=K \sin (-\varphi)=-I_{0} \\
& (8) \rightarrow e^{-\alpha \frac{T_{\mathrm{s}}}{2}} K\left[\sin \left(\omega_{\mathrm{d}} \frac{T_{\mathrm{s}}}{2}\right) \cos (-\varphi)+\cos \left(\omega_{\mathrm{d}} \frac{T_{\mathrm{s}}}{2}\right) \sin (-\varphi)\right]=+I_{0}
\end{aligned}
$$

Dividing (9) by (7) we obtain:

$$
\begin{aligned}
& \frac{e^{-\frac{\pi \omega_{0}}{2 Q \omega_{\mathrm{s}}}} K\left[\sin \left(\pi \frac{\omega_{\mathrm{d}}}{\omega_{\mathrm{s}}}\right) \cos (-\varphi)+\cos \left(\pi \frac{\omega_{\mathrm{d}}}{\omega_{\mathrm{s}}}\right) \sin (-\varphi)\right]}{K \sin (-\varphi)}=-1 \\
& e^{-\frac{\pi}{2 Q} \frac{\omega_{0}}{\omega_{\mathrm{s}}}}\left[\frac{\sin \left(\pi \frac{\omega_{\mathrm{d}}}{\omega_{\mathrm{s}}}\right)}{\tan (\varphi)}-\cos \left(\pi \frac{\omega_{\mathrm{d}}}{\omega_{\mathrm{s}}}\right)\right]=1
\end{aligned}
$$

and finally: $\varphi=\arctan \left(\frac{\sin \left(\pi \frac{\omega_{\mathrm{d}}}{\omega_{\mathrm{s}}}\right)}{\mathrm{e}^{+\frac{\pi}{2 Q} \frac{\omega_{0} \omega_{\mathrm{d}}}{\omega_{\mathrm{d}}}}+\cos \left(\pi \frac{\omega_{\mathrm{d}}}{\omega_{\mathrm{s}}}\right)}\right)$

Relation (12) is graphed in Fig. 5 for $Q=3,4$ and 5 and shows considerably different behavior than (2) and Fig. 3. The function is not monotonous and it "oscillates" below resonance $\left(x=\omega_{\mathrm{s}} / \omega_{\mathrm{d}}<1\right)$ having negative, but also positive values for $\varphi$.

To verify this rather strange dependence, Fig. 6 gives PSpice simulation results of steady-state for several values of the switching frequency below and above resonance. Phase angles measured in these waveforms match and verify results obtained by (12). Also, the current waveform for $f_{\mathrm{s}}=0.5 \cdot f_{\mathrm{d}}$ or $f_{\mathrm{s}}$ $=0.6 \cdot f_{\mathrm{d}}$ shows that it is very much distorted deep below resonance, the first harmonic is no longer dominant, which reflects to the amount of active power transferred to the load. This explains why below-resonance mode of power control is less desirable. The first diagram in Fig. 6 for $f_{\mathrm{s}}=0,5 f_{\mathrm{d}}$ shows that (12) gets zero values every time the switching period $T_{\mathrm{s}}$ is multiple of the dumping one $T_{\mathrm{d}}$, in this case $T_{\mathrm{s}}=2 T_{\mathrm{d}}$.

\section{Comparison of the sine and the pulse excitation cases}

A comparison of the phase angle $\varphi$ dependence on $\omega_{\mathrm{s}}$ in both cases, with sinusoidal and pulse excitation, is given in Fig. 7. The switching angular frequency $\omega_{\mathrm{s}}$ is normalized, in the first case with the resonant $\omega_{0}$, and in the second with the dumping angular frequency $\omega_{\mathrm{d}}$. The figure shows that there is a considerable difference, especially further away from the resonance point. However, making PSpice simulations and measuring the phase angle time equivalents $t_{\varphi}$, it was noticed that they have very close values in the above-resonance region as can be clearly seen in Fig. 8. Analyzing this fact lead us to a very interesting conclusion. Namely $t_{\varphi}$ is calculated in a different way in both cases. When the circuit excitation is sinusoidal, the current is in the form:

$$
\begin{gathered}
i(t)=I_{\text {max }} \sin \left(\omega_{\mathrm{s}} t-\varphi\right)=I_{\max } \sin \left[\omega_{\mathrm{s}}\left(t-t_{\varphi}\right)\right] \\
t_{\varphi}=\frac{\varphi}{\omega_{\mathrm{s}}}=\varphi \frac{T_{\mathrm{s}}}{2 \pi}
\end{gathered}
$$

and

In the second case with voltage pulses excitation, we have:

and

$$
i(t)=e^{-\alpha t} K \sin \left(\omega_{\mathrm{d}} t-\varphi\right)=e^{-\alpha t} K \sin \left[\omega_{\mathrm{d}}\left(t-t_{\varphi}\right)\right]
$$

Relations (14) and (16) are similar, but profoundly different: $\omega_{\mathrm{d}}$ and $T_{\mathrm{d}}$ are constants determined by the circuit parameters, while $\omega_{\mathrm{s}}$ and $T_{\mathrm{s}}$ are variables that are changed by the control method and are used as $x$-axis in Figs. 7 and 8. This also shows that in the case with voltage pulses, the correct way to measure and calculate the phase angle is by using (16) which is not taken into account in many analysis and papers.

\section{NEW METHOD DEVELOPMENT}

The main objective of the control method is to adjust the switching frequency so that the desired phase angle and power transfer are obtained. To do so, the feedback circuit in Fig. 1 


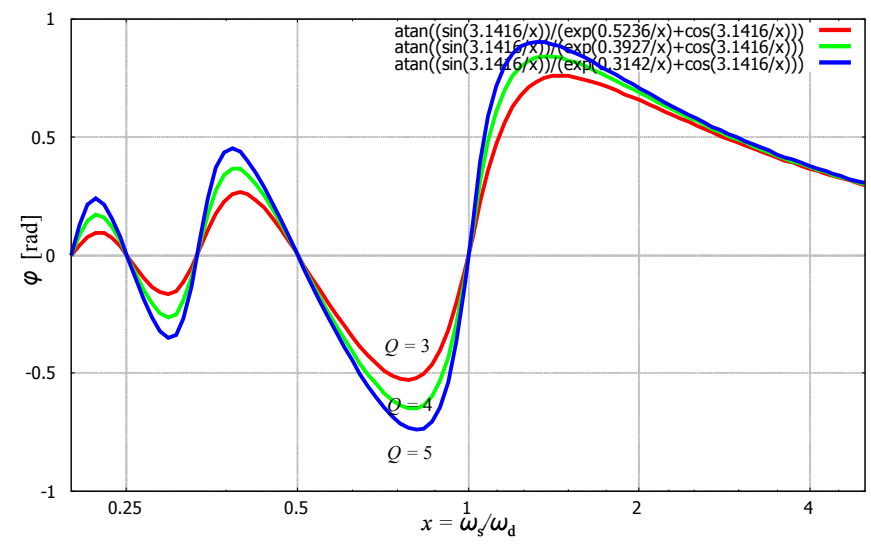

Fig. 5. Dependence of the phase angle $\varphi$ on the normalized value $\omega_{\mathrm{s}} / \omega_{\mathrm{d}}$ for $Q=3,4$ and 5, when excited by voltage pulses.
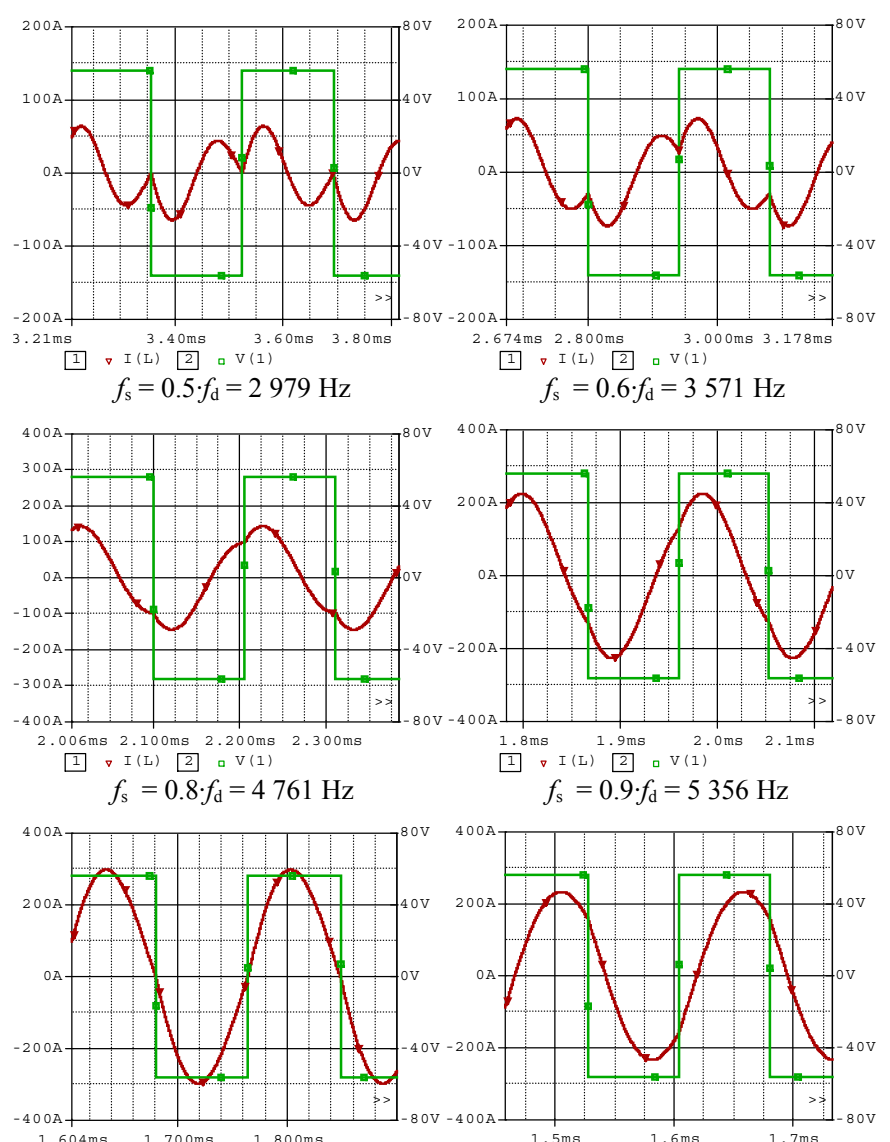

$1.604 \mathrm{~ms} 1.700 \mathrm{~ms} 1.800 \mathrm{~ms}$
$1 \nabla \mathrm{I}(\mathrm{L}) 2 \mathrm{2} \cdot \mathrm{V}(1)$
$f_{\mathrm{s}}=1.0 \cdot f_{\mathrm{d}}=5951 \mathrm{~Hz}$
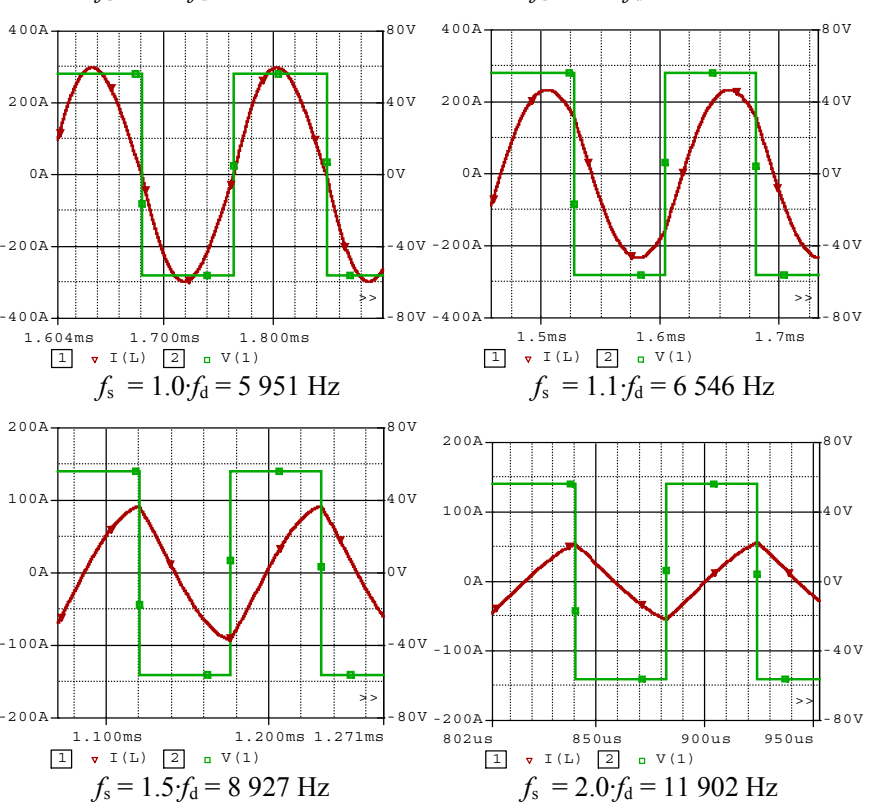

Fig. 6. Steady state voltage and current waveforms below and above resonance $(R=0.24 \Omega, L=26.5 \mu \mathrm{H}, C=26.6 \mu \mathrm{F}$ and $Q=4)$.

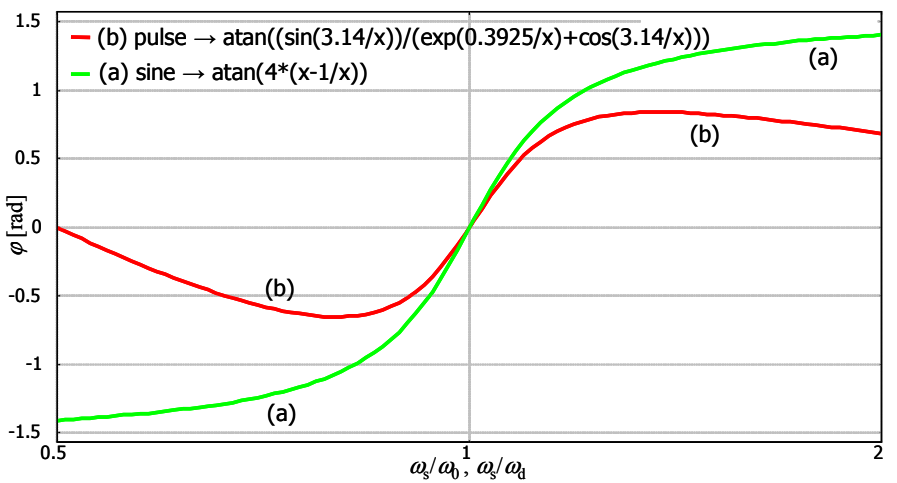

Fig. 7. Comparison of the phase angle $\varphi$ dependence on $\omega_{\mathrm{s}}$ for $Q=4$ :

(a) sinusoidal excitation, $x=\omega_{\mathrm{s}} / \omega_{0}$, (b) pulse excitation, $x=\omega_{\mathrm{s}} / \omega_{\mathrm{d}}$.

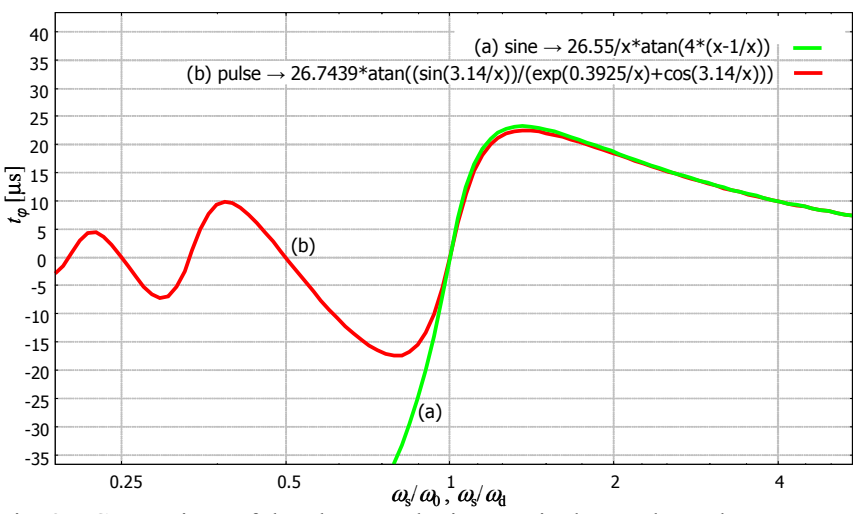

Fig. 8. Comparison of the phase angle time equivalent $t_{\varphi}$ dependence on $\omega_{\mathrm{s}}$ :

(a) sinusoidal excitation, $x=\omega_{\mathrm{s}} / \omega_{0}$, (b) pulse excitation, $x=\omega_{\mathrm{s}} / \omega_{\mathrm{d}}$.

has possibilities to measure the time between current zero crossings and instants when the switches are turned on or off. This means that the control method as input has the values of the previous cycle switching period $T_{s, i-1}$ and the current cycle phase angle time equivalent $t_{\varphi, i}$. Having these measured values, the method should determine the new switching frequency $T_{s, i}$ at which the $\varphi_{i}$ and $t_{\varphi, i}$ have the desired or the reference values.

To determine $T_{\mathrm{d}, i}$ knowing $T_{\mathrm{s}, i-1}$ and $t_{\varphi, i}$, the implicit equation (18) can be used, that now has the form:

$$
t_{\varphi, i}=\frac{T_{\mathrm{d}, i}}{2 \pi} \operatorname{arctg}\left(\frac{\sin \left(\frac{\pi}{T_{\mathrm{d}, i}} T_{\mathrm{s}, i-1}\right)}{\mathrm{e}^{+\frac{\pi}{2 Q} T_{\mathrm{s}, i-1}}+\cos \left(\frac{\pi}{T_{\mathrm{d}, i}} T_{\mathrm{s}, i-1}\right)}\right)
$$

Then $T_{s, i}$ is determined using now the implicit equation (12) and $T_{d, i}$ and $\varphi_{\text {ref }}$ as known parameters:

$$
\varphi_{\text {ref }}=\operatorname{arctg}\left(\frac{\sin \left(\frac{\pi}{T_{\mathrm{d}, i}} T_{\mathrm{s}, i}\right)}{\mathrm{e}^{+\frac{\pi}{2 Q} T_{\mathrm{s}, i}}+\cos \left(\frac{\pi}{T_{\mathrm{d}, i}} T_{s, i}\right)}\right)
$$

Finally, the interval $T_{\text {delay }, i}$ is calculated using (1):

$$
T_{\text {delay }, i}=\frac{T_{\mathrm{s}, i}}{2}-t_{\varphi, i}
$$

All these calculations should be solved numerically before the positive half-period ends, i.e. during $T_{\text {delay }}$ time. Having in 
mind that $T_{s} / 2$ is less than $100 \mu \mathrm{s}$ and $t_{\varphi}$ in the order of $10 \mu \mathrm{s}$, it is not possible to do the calculations with low cost microcontrollers, so the equations need to be simplified.

\section{A. Linearization of phase angle equations}

One common approach in electrical engineering and electronics to simplify nonlinear equations is linearization using derivates at the operating point $(x=1)$. This way a simple linear equation is obtained that matches the nonlinear curve very good around the operating point, and no so well away from that point. In the above-resonance region this linearization can be done on any of the two excitation cases since the curves almost overlap. Having in mind that the method uses time intervals $\left(T_{s}\right.$ and $\left.t_{\varphi}\right)$ the linearization is done on the $t_{\varphi}=f\left(T_{s}\right)$ function, resulting in (23) and graphically presented in Fig. 9.

$$
t_{\varphi}=\frac{Q}{\pi} T_{\mathrm{d}}\left(1-\frac{T_{\mathrm{s}}}{T_{\mathrm{d}}}\right)
$$

Another way is to make linearization is to position the linear dependence in such a way so that there is smallest deviation from the curve on the entire range of $t_{\varphi}$ change. To do so, the linear equation has to have a smaller slope, which can be achieved by multiplication by an additional coefficient $a<1$, as in (24) and illustrated in Fig. 9 with the dashed line for $a=0.75$ and the doted line for $a=0.5$.

$$
t_{\varphi}=a \frac{Q}{\pi} T_{\mathrm{d}}\left(1-\frac{T_{\mathrm{s}}}{T_{\mathrm{d}}}\right)
$$

\section{B. Algorithm for the proposed direct phase control method}

Based on the above analysis the method for the direct phase control consist of an algorithm with 8 steps:

1. Switch-off T1 and T2, and switch-on T3 and T4, (positive half-period starts, reset the $t_{\varphi, i}$ register);

2. Wait for current zero crossing moment $i(t)>0$ and measure time interval $t_{\varphi, i}$;

3. Calculate $T_{\text {delay }, i}$ using following equations:

$$
\begin{gathered}
T_{\mathrm{d}, i}=T_{\mathrm{s}, i-1}+\frac{\pi}{Q} t_{\varphi, i}, t_{\varphi, \text { ref }, i}=\frac{\varphi_{\text {ref }}}{2 \pi} T_{\mathrm{d}, i}, \\
T_{\mathrm{s}, i}=T_{\mathrm{d}, i}-\frac{\pi}{Q} t_{\varphi, \text { ref }, i}, T_{\text {delay }, i}=\frac{T_{\mathrm{s}, i}}{2}-t_{\varphi, i}
\end{gathered}
$$

4. Wait for time interval $T_{\text {delay }, i}$;

5. Switch-on T1 and T2, and switch-off T3 and T4 (negative half-period starts, reset the $t_{\varphi, i}$ register);

6. Wait for current zero crossing moment $i(t)<0$ and measure time interval $t_{\varphi, i}$;

7. Calculate $T_{\text {delay }, i}$ using (25);

8. Wait for time interval $T_{\text {delay }, i}$ and go to step 1 .

The algorithm is graphically shown in Fig. 10.

\section{VERIFICATION}

To verify the improved method series of investigations have been done including mathematical calculations, PSpice simulations, code simulations in Proteus and hardware implementation. The method was tested in situations when there is abrupt change of $L$ and $R$ values, as well as with abrupt change

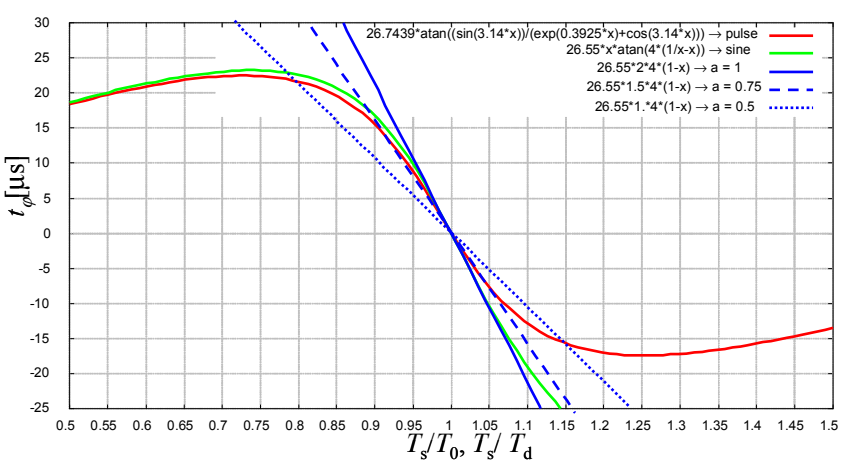

Fig. 9. Linearization of the phase angle time equivalent $t_{\varphi}$ dependence on $T_{\mathrm{s}}$.

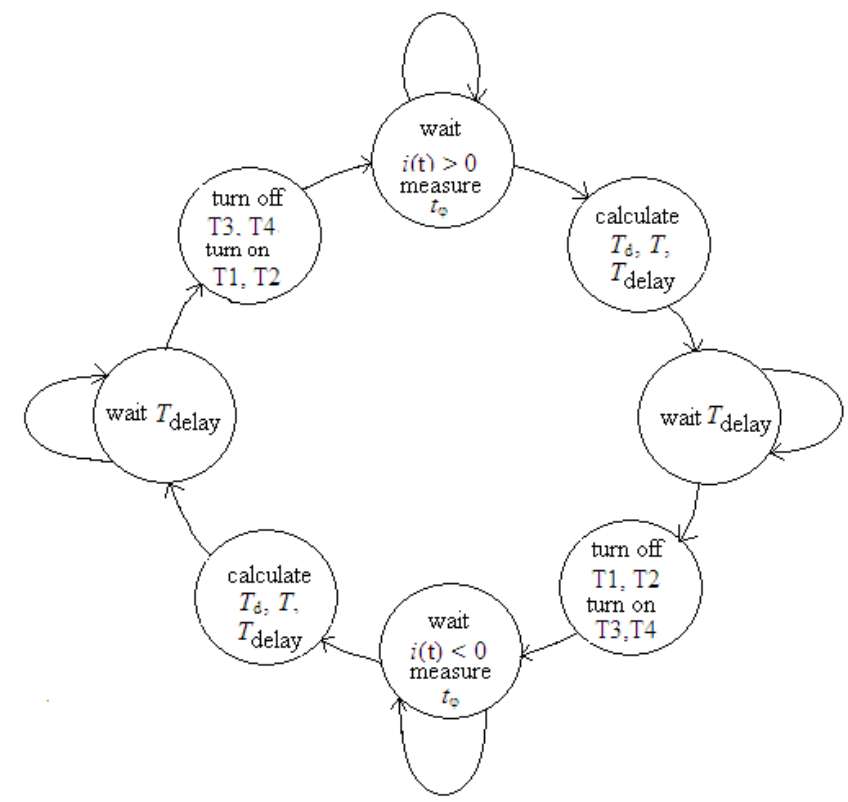

Fig. 10. Block diagram of the control algorithm.

of the reference angle $\varphi_{\text {ref. }}$. Due to limited space in this paper only few of the simulations and experiments are presented.

Fig. 11 shows results for the change of $\varphi_{i}$ obtained by a PSpice simulation of the method when there are simultaneous abrupt changes of the inductance value $L$ from $26.5 \mu \mathrm{H}$ to 31.5 $\mu \mathrm{H}$ and the resistance $R$ from $0.24 \Omega$ to $0.29 \Omega$, with the reference phase angle set to $\varphi_{\text {ref }}=5^{\circ}$. Results obtained for the method in $[10,11]$ are shown on the same graph to make a comparison. The amplitude of the oscillation of $\varphi_{i}$ with the new method is smaller, and also the transient interval is shorter. A comparison and verification when the reference angle $\varphi_{\text {ref }}$ is abruptly changed from $5^{\circ}$ to $35^{\circ}$ is shown in Fig. 12 . Again, the amplitude of oscillation of $\varphi_{i}$ before it settles to the new value with the new method is smaller and the transient interval is shorter, too.

Practical verification was done with algorithm implementation on a PIC18F452 microcontroller and an IGBT full-bridge resonant inverter prototype shown in Fig. 13 [14, 15]. The prototype initially works with $f_{\mathrm{s}}=1268 \mathrm{~Hz}\left(T_{\mathrm{s}}=788 \mu \mathrm{s}\right)$, resonant circuit parameters are $R=0.5 \Omega, L=315 \mu \mathrm{H}, C=55 \mu \mathrm{F}$ $(Q=4.77)$ and the control circuitry is set to work with $\varphi_{\text {ref }}=$ $22^{\circ}\left(t_{\varphi}=50.80 \mu \mathrm{s}\right)$ to have output power of 40VA (Fig.14.a). 
The inductor in this experiment is a coil with a moving ferromagnetic coil. When the coil is moved so that its inductance changes to $L=426 \mu \mathrm{H}(35 \%$ change $)$, the control algorithm successfully changes the switching frequency to $f_{\mathrm{s}}=1207 \mathrm{~Hz}$ $\left(T_{\mathrm{s}}=828 \mu \mathrm{s}\right)$ with $\varphi=21.6^{\circ}\left(t_{\varphi}=58 \mu \mathrm{s}\right)($ Fig. 14.b).

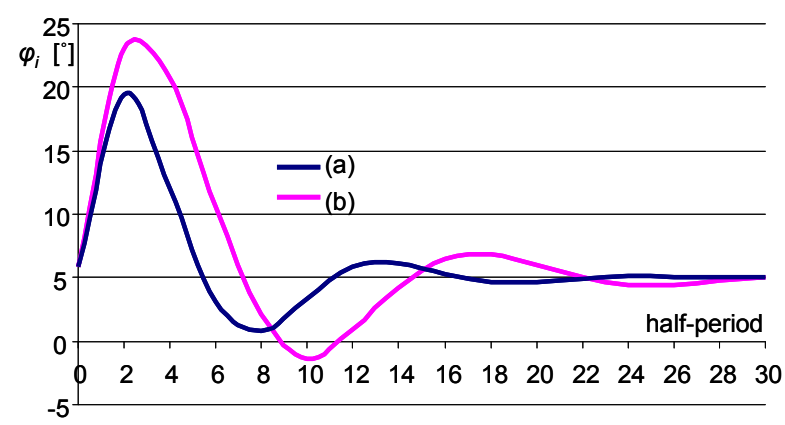

Fig. 11. PSpice results of the change of $\varphi_{i}$ due to an abrupt changes of $L$ from $26.5 \mu \mathrm{H}$ to $31.5 \mu \mathrm{H}$ and $R$ from $0.24 \Omega$ to $0.29 \Omega$ whit $\varphi_{\text {ref }}=5^{\circ}$ : (a) the new method and (b) the method in $[10,11]$.

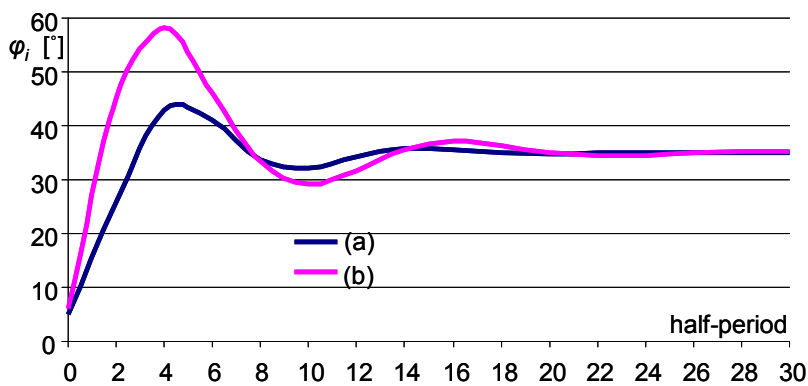

Fig. 12. PSpice results of the change of $\varphi_{i}$ due to an abrupt change of $\varphi_{\text {ref }}$ from $5^{\circ}$ to $35^{\circ}$ : (a) the new method and (b) the method in $[10,11]$.

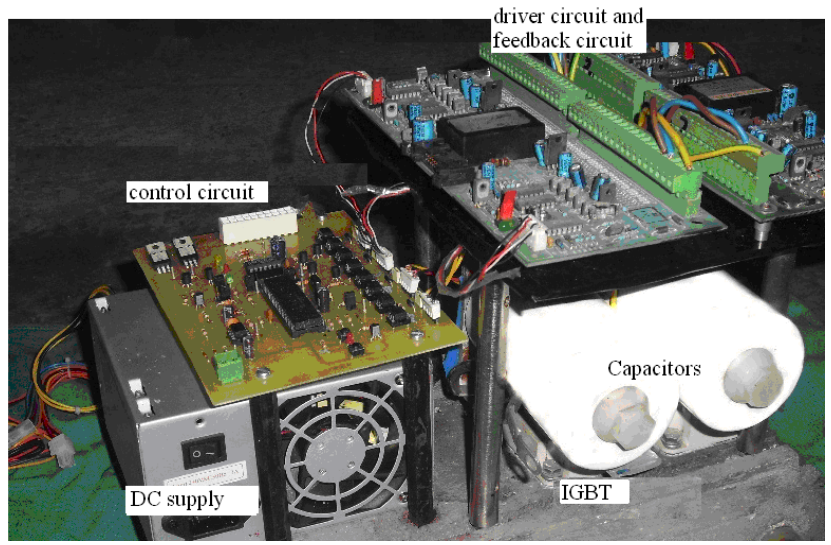

Fig. 13. Prototype of the series-resonant full-bridge inverter with the feedback, control and drive circuits.

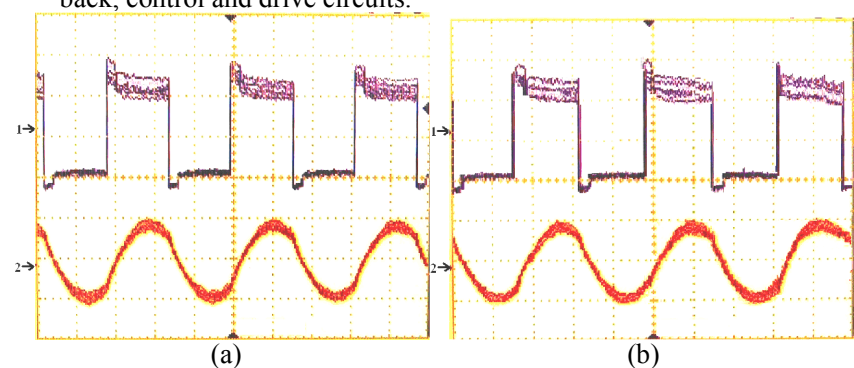

Fig. 14. Oscillograms of the prototype $v_{\text {out }}(\mathrm{t})$ and $i_{\text {out }}(\mathrm{t})$ : (a) $L=315 \mu \mathrm{H}$ with $T_{s}$ $=788 \mu \mathrm{s}$, (b) after inductance change to $L=426 \mu \mathrm{H}$ the period adjusts to $T_{s}=828 \mu \mathrm{s}$. Ch1: $5 \mathrm{~V} / \mathrm{div}, 250 \mu \mathrm{s} / \mathrm{div} ; \mathrm{Ch} 2: 2 \mathrm{~A} / \mathrm{div}, 250 \mu \mathrm{s} / \mathrm{div}$.

\section{CONCLUSION}

The analysis of the series resonant circuit excited by a square pulse voltage, obtained from a full-bridge converter, shows a considerably different dependence of the current phase angle on the switching frequency than in the case of sinusoidal excitation. More over, the phase angle in this case has to be calculated in respect to the damping frequency, which depends on circuit parameters, rather then in respect to the switching one, which is constantly varied by the control method. This fact is usually neglected in many analysis and papers.

Phase control provides reliable drive of the series-resonant inverters in the presence of large dynamic changes in the load impedance. Based on above analysis, improvements to the direct phase control method are made. Linearization of the method equations has been made to facilitate its implementation with low cost microcontrollers. An algorithm for digital implementation and method verification with simulations and a prototype are presented at the end of the paper.

\section{REFERENCES}

[1] Y. Deshmukh, Industrial Heating: Principles, Techniques, Materials, Applications and Design, Taylor and Francis Group, Boca Raton, 2005.

[2] V. Rudnev, D. Loveless, R. Cook, M. Black, Handbook of Induction Heating, Madison Heights, Michigan, USA, 2003.

[3] G. E. Totten, Steel Head Treatment, 2nd ed., Portland State University, Oregon USA, 2006.

[4] E. Rapoport, Y. Pleshitseva, Optimal Control of Induction Heating Processes, CRC Press, 2007

[5] H. M. Unver, M. T. Aydemir, "Power and frequency control in a $60 \mathrm{~kW}$ induction steel heating furnaces through PLC", National Scientific Meetings, Ankara, Turkey, 9-12 September 2002.

[6] Y. Kwon, S. Yoo, D. Hyun, "Half-bridge series resonant inverter for induction heating applications with load-adaptive PFM control strategy", Applied Power Electronics Conference and Exposition, pp. 575-581, Dallas, TX, USA, 14-18 Mar 1999.

[7] L. Grajales, F. C. Lee, "Control system design and small-signal analysis of a phase-shift-controlled series-resonant inverter for induction heating", Power Electronics Specialists Conference-PESC'95, Volume 1, pp. 450-456, 1995.

[8] W.-H. Ki, J. Shi, E. Yau, P. K. T. Mok, and J. K. O. Sin, "Phase controlled dimmable electronic ballast for fluorescent lamps," Power Electronics Specialists Conference-PESC'99, pp. 1121-1125, 1999.

[9] P. Viriya T. Thomas, "Power transfer characteristics of a phase-shift controlled ZVS inverter for the application of induction heating", Int. Power Electron. Conf.-IPEC, pp. 423-428, San Francisco, CA, 2000.

[10] Y. Yin, Z. Regan, "Digital phase control for resonant inverters", IEEE Power Electronics Letters, vol. 2, no. 2, pp. 51-54, June 2004.

[11] Y. Yin, M. Shirazi, R. Zane, "Electronic ballast control IC with digital phase control and lamp current regulation", IEEE Trans. Power Electron., vol. 23, no. 1, pp. 11-18, Jan 2008.

[12] F. J. Azcondo, R. Zane, and C. Branas, "Design of resonant inverters for optimal efficiency over lamp life in electronic ballast with phase control," IEEE Trans. Power Electron., vol. 22, no. 3, pp. 815-823, 2007.

[13] G. Stefanov, Lj. Karadzinov, "Phase controlled bridge converter with serial resonant load", 14th International Power Electronics and Motion Control Conference EPE-PEMC 2010, pp. T3 81-87, Ohrid, Macedonia, 6-8 Sep 2010.

[14] G. Stefanov, Lj. Karadzinov, T. Dzhekov, "Design of an IGBT bridge converter for serial resonant load", 14th International Power Electronics and Motion Control Conference, EPE-PEMC 2010, pp. T9 19-26, Ohrid, Macedonia, 6-8 Sep 2010.

[15] G. Stefanov, "Resonant Converter for Induction Heating of Metals with Improved Efficiency", Ph.D. Thesis, Sts. Cyril and Methodius University, Skopje, Macedonia, 2014. 


\section{PROCEEDINGS EUROCON 2015}

Salamanca, Spain $8^{\text {th }}-11^{\text {th }}$ September 


\section{EUROCON 2015}

08-11 September 2015

Salamanca, Spain

ISBN: 978-1-4799-8569-2

IEEE Catalog Number: CFP15EUR-CDR

Editors:

Jan Haase, Helmut Schmidt University of the Federal Armed Forces, Germany

Athanasios Kakarountas, TEl of lonian Islands, Greece

Manuel Graña, ENGINE centre, Wroclaw University of Technology, Poland

Jesús Fraile-Ardanuy, Universidad Politécnica de Madrid, Spain

Carl James Debono, University of Malta, Malta

Héctor Quintián, University of Salamanca, Spain

Emilio Corchado, University of Salamanca, Spain

EuroCon 2015 is organized by: 


\section{EuroCon 2015}

Copyright ( 2015 by the Institute of Electrical and Electronics Engineers, Inc. All rights reserved.

Copyright and Reprint Permissions:

Abstracting is permitted with credit to the source. Libraries are permitted to photocopy beyond the limit of U.S. copyright law for private use of patrons those articles in this volume that carry a code at the bottom of the first page, provided that the per-copy fee indicated in the code is paid through the Copyright Clearance Center, 222 Rosewood Drive, Danvers, MA 01923.

For other copying, reprint, or republication permission, write to IEEE Copyrights Manager, IEEE Service Center, 445 Hoes Lane, Piscataway, NJ 08854. All rights reserved.

IEEE Catalog Number: CFP15EUR-CDR

ISBN: 978-1-4799-8569-2 


\section{Welcome}

It is a great pleasure to welcome you to EuroCon 2015 in the historical city of Salamanca (Spain), declared a UNESCO world Meritage Site in 1988 and European Capital of Culture in 2002.

The IEEE Region 8 EuroCon 2015 Conference is a premier forum for the exchange of ideas, open and direct discussion on the development of the Circuits and Systems, Multimedia, Information and Communication Technology and energy and power systems. It has achieved a considerable success during the past 15 editions covering majority of the fields in the area of electrical engineering.

EUROCON 2015 received more than 250 technical submissions during several months. After a rigorous peer-review process, the International Program Committee selected 141 papers, which are published in this conference proceedings. The five finalists of the IEEE Region 8 student paper contest will also present their work during Eurocon 2015 Conference.

The selection of papers was extremely rigorous in order to maintain the high quality of the conference and we would like to thank the Program Committee for their hard work in the reviewing process. This process is very important to the creation of a conference of high standard and the EuroCon conference would not exist without their help.

The large number of submissions is certainly not only to testimony to the vitality and attractiveness of the field but an indicator of the interest in the EuroCon conferences themselves.

EuroCon 2015 enjoyed outstanding keynote speeches by distinguished guest speakers: Prof. Francisco Herrera - University of Granada (Spain), Prof. Marios M. Polycarpou - University of Cyprus (Cyprus), Prof. John Thompson -University of Edinburgh (UK), Mr. Isidro Laso -European Commission and Mr. Costas Stasopoulos - IEEE Region 8 Director (Cyprus).

The editors,

Jan Haase, Helmut Schmidt University of the Federal Armed Forces, Germany

Athanasios Kakarountas, TEl of Ionian Islands, Greece

Manuel Graña, ENGINE centre, Wroclaw University of Technology, Poland

Jesús Fraile-Ardanuy, Universidad Politécnica de Madrid, Spain

Carl James Debono, University of Malta, Malta

Héctor Quintián, University of Salamanca, Spain

Emilio Corchado, University of Salamanca, Spain 


\section{Committees}

\section{General Chair}

Emilio Corchado- University of Salamanca, Spain

\section{Honorary Chairs}

Alfonso Fernández Mañueco - Mayor of Salamanca, Spain

Costas M. Stasopoulos- IEEE Director Region 8

\section{Technical Programme Committee}

TPC Co-chairs

Carl James Debono - University of Malta, Malta

Magdalena Salazar- Universidad Carlos III de Madrid, Spain

Manuel Castro - UNED, Spain

Manuel Graña - ENGINE centre, Wroclaw University of Technology, Poland

\section{Publicity Co-chairs}

Matej Zajc- University of Ljubljana, Slovenia

Marios Antoniou- CYTA, Cyprus

Ali El-Mousa - University of Jordan, Jordan

Shaun Kaplan - CapeSoft, South Africa

\section{Track Chairs}

Jan Haase - Track: Smart Cities - Helmut Schmidt University of the Federal Armed Forces, Germany

Athanasios Kakarountas - Track: Circuits and Systems for Signal Processing - TEl of Ionian Islands, Greece

Manuel Graña - Track: Information and Communication ENGINE centre, Wroclaw University of Technology, Poland

Jesús Fraile-Ardanuy - Track: Power Resources and Systems - Universidad Politécnica de Madrid, Spain

\section{Organizing Committee}

Jesús Fraile-Ardanuy - Universidad Politécnica de Madrid, Spain

Ana Collado - CTTC, Spain

Victorino Franco - University of Seville, Spain

Alfonso Lago - University of Vigo, Spain

Mislav Grgic- University of Zagreb, Croatia

Igor Kuzle- University of Zagreb, Croatia

Peter Nagy- HTE, Hungary

Álvaro Herrero - University of Burgos, Spain

Bruno Baruque- University of Burgos, Spain

Héctor Quintián - University of Salamanca, Spain

Javier Andión - Technical University of Madrid, Spain 


\section{Program Committee}

A

A. Lipsky, Ariel University, Israel

A.I. Gonzalez, ATC-FISS-UPV/EHU, Spain

Aaron Suberbiola, UPV / EHU, Spain

Abdellah Touhafi, Vrije Universiteit Brussel, Belgium

Abel Paz-Gallardo, Ciemat, Spain

Adesekoa. Ayeni, University of llorin, Nigeria

Alberto Tessarolo, Electrical Engineering Dept., University of Trieste, Italy

Alberto Bollero, IMDEA, Nanociencia, Spain

Aleksandar Janjic, University of Nis, Serbia

Aleksandar Neskovic, School of Electrical Engineering -

University of Belgrade Serbia, Serbia

Alexander Sudnitson, Tallin University of Technology, Estonia

Alexandra Posoldová, Griffith University, Australia

Alexandre Savio, Universidad del País Vasco, Spain

Alicia D'Anjou, Basque Country University UPV/EHU, Spain

Alladi Anuradha, Tata Consultancy Services, India

Almir Badnjevic, Verlab Ltd Sarajevo, Bosnia and Herzegovina

Athanasios Milidonis, Technological Educational Institute of Athens, Greece

Alois Knoll, Technische Universität München, Germany

An Braeken, Erasmus University College, Brussels, Belgium,

Belgium

Ana González-Marcos, Universidad de la Rioja, Spain

Antonio Alexandridis, University of Patras, Greece

Antonio Lazaro, Universitat Rovira i VIrgili, Spain

Antonio Lopez-Martin, Public University of Navarra, Spain

Antonio Plaza, Universidad de Extremadura, Spain

Apostolos Georgiadis, CTTC, Spain

Arnaldo Oliveira, Universidade de Aveiro - DETI / IT, Portugal

Arturas Serackis, Vilnius Gediminas Technical University, Lithuania

Athanasios Kakarountas, TEl of Ionian Islands, Greece

\section{B}

Babak Kashanizadeh, Sharif University of Technology, Iran

Bahubalindruni Pydi, University of Porto, Portugal

Begović Alen, BH Telecom, Bosnia and Herzegovina

Bessie Malila, University of cape town, South Africa

Beste Ustubioglu, Karadeniz Tecnical University, Turkey

Biljana Stojkoska, University "Ss.Cyril and Methodius", Macedonia

Borja Ayerdi, UPV/EHU, Spain

Borja Fernandez-Gauna, University of Basque Country, Spain

\section{C}

Carl James Debono, University of Malta, Malta
Carlos Correa, Universidad De La Salle, Colombia

Carlos Lopez, Technical University of Madrid, Spain

Carlos Travieso, University of Las Palmas de Gran Canaria, Spain

Carsimamovic Adnan, NOS BiH, Bosnia and Herzegovina

Christian Galea, University of Malta, Malta

Ciprian Sorandaru, POLITEHNICA University of TIMISOARA, Romania

Claudia-Adina Dragos, Politehnica University of Timisoara, Romania

Constantin Barbulescu, Politehnica University of Timișoara, Romania

Cornel Turcu, University of Suceava, Romania

Cristina Turcu, Stefan cel Mare University of Suceava, Romania

D

Dalius Navakauskas, Vilnius Gediminas Technical University, Lithuania

Damir Jakus, University of Split, Croatia

Dan Jigoria-Oprea, Politehnica University of Timisoara, Romania

Danijel Pavković, University of Zagreb, Croatia

Danko Ivosevic, University of Zagreb, Croatia

Darya Chyzhyk, University of Basque Country, Spain

David Nedeljkoviu, University of Ljubljana, Slovenia

David Jiménez, Universidad Politécnica de Madrid, Spain

Dimitrios Tseles, Technological Educational Institute of Piraeus,

Greece

Dimitrios Schinianakis, University of Patras, Greece

Dimitris Bakalis, University Of Patras, Greece

Dimitris Karampoulas, Open University, United Kingdom

Diptanil Debbarma, Eindhoven University of Technology, Netherlands

Domenico Zito, Tyndall, Ireland

Dumitru Toader, University Politehnica of Timisoara, Romania

Dusko Lukac, University of Applied Sciences, Germany

\section{E}

Elena Zaitseva, University of Zilina, Slovakia

Emilio Corchado, University of Salamanca, Spain

Enis Kocan, University of Montenegro, Montenegro

Enrique Romero-Cadaval, University of Extremadura, Spain

Eraldo Banovac, HERA, Croatia

Erik Markert, TU Chemnitz, Germany

Ervin Varga, Faculty of Technical Sciences Novi Sad, Serbia

Evangelos Vassalos, University of Patras, Greece

Eya Mezghani, REGIM-Lab's, Tunisia

Fernando Pescador, Technical University of Madrid, Spain 


\section{$\mathbf{F}$}

Flaviu Mihai Frigura-lliasa, Politehnica University of Timisoara, Romania

Florin Molnar-Matei, Politehnica University of Timisoara, Romania

Fragkiskos Pentaris, Brunel University, United Kingdom

Francesco Cannone, Politecnico di Bari, Italy

Francesco Leporati, University of Pavia, Italy

Francisco Arcega, University of Zaragoza, Spain

Francisco Falcone, Universidad Pública de Navarra, Spain

Francisco Ortuno, University of Granada, Spain

Francisco R. Soriano, University of Valencia, Spain

\section{G}

Gaspare Galati, University of Rome Tor Vergata, Italy

Gergely Mezei, BUTE, Hungary

Gheorghe Vuc, Politehnica University from Timisoara, Romania

Ghulam Muhammad, King Saud University, Saudi Arabia

Gianfranco Chicco, Politecnico di Torino, Italy

Gill Lacey, Northumbria University, United Kingdom

Goikoetxea Ander, Mondragon Unibertsitatea, Spain

Goranb. Markoviü, University of Belgrade, Serbia

Guilherme Corrêa, Universidade Federal de Pelotas, Brazil

\section{H}

Hao Cai, Telecom Paristech, France

Harris Michail, Cyprus University of Technology, Cyprus

Hasan Fleyeh, Dalarna University, Sweden

Hassan Charaf, Budapest University of Technology and Economy, Hungary

Hector Pomares, University of Granada, Spain

Héctor Quintián, University of Salamanca, Spain

Henning Olesen, AAU / CMI, Denmark

\section{I}

Ignacio García-Fernández, Universitat de Valencia, Spain

Ignacio Rojas, University of Granada, Spain

Igor Kuzle, University of Zagreb, Croatia

Igor Radusinovic, Montenegro Univ., Yugoslavia

lleana-Diana Nicolae, University of Craiova, Romania

Ilya Galkin, Riga Technical University, Latvia

Iouliia Skliarova, University of Aveiro, Portugal

Iva Bojic, Massachusetts Institute of Technology, USA

Ivan Androcec, Hrvatska elektroprivreda d.d., Croatia

Ivan Rajšl, University of Zagreb, Croatia

Ivan Kastelan, University of Novi Sad, Serbia

Ivan Macia, Vicomtech, Spain

Ivars Beinarts, LATNET, Latvia

\section{J}

J. David Nuñez-Gonzalez, University of Basque Country, Spain
Jaime Ramirez-Angulo, New Mexico State University, USA

Jan Verveckken, Catholic University of Leuven, Belgium

Jan Haase, Helmut Schmidt University of the Federal Armed

Forces, Germany

Jarmila Pavlovičová, Slovak University of Technology in Bratislava, Slovakia

Javier Perez, Genomics and Bioinformatics Platform of Andalusia (GBPA), Spain

Jean Marie Darmanin, University of Malta, Malta

Jeanmarie Vella, University of Malta, Malta

Jesus Alonso, University of Las Palmas de Gran Canaria, Spain

Jesus Fraile-Ardanuy, Universidad Politecnica de Madrid, Spain Jianguo Ding, University of Skövde, Sweden

Joao Matos, Instituto de Telecomunicacoes - Polo de Aveiro,

Portugal

Joao Paulo Papa, UNESP - Univ Estadual Paulista, Brazil

Jon Andoni Barrena, Mondragon University, Spain

Jordi Sole-Casals, University of Vic, Spain

Jordi Solé-Casals, University of Vic - Central University of Catalonia, Spain

Jorge Sevilla, University of Extremadura, Spain

Jose Antonino-Daviu, Universitat Politecnica de Valencia, Spain

José Ángel Sánchez, Technical University of Madrid, Spain José M. de La Rosa, CSIC, Spain

Jose Manuel Lopez-Guede, Basque Country University, Spain José Miguel Franco-Valiente, Ciemat, Spain

Josu Arrinda, Ingeteam Technology, Spain

Josu Maiora, University of the Basque Country, Spain

Jozef Pokusny, Pokusna, Slovakia

Juan C. Dueñas, Universidad Politécnica de Madrid, Spain Juan Pedro Lopez, Universidad Politecnica de Madrid, Spain Juergen Mottok, LaS ${ }^{3}$, OTH Regensburg, Germany

Julia Merino, Tecnalia, Spain

\section{K}

Kaminski Marcin, Wrocław University of Technology, Poland Karmele López, University of the Basque Country, Spain Khaled Mohamed, Mentor Graphics, Egypt Kim Gruttner, OFFIS, Germany Krunoslav Ivešić, FER, Croatia Krzysztof Szabat, Wrocław University of Technology, Poland Ksenia Lomovskaya, National Research University of Electronic Technology (MIET), Russia Kuljaca Ognjen, Brodarski institut, Croatia

\section{L}

Lakhlef Hicham, University Of Franche-Comte, France Lars Svensson, Chalmers University of Technology, Sweden Larysa Globa, National Technical University of Ukraine "KPI", Ukraine Laszlo Lengyel, BME DAAI, Hungary Leire Ozaeta, University of the Basque Country, Spain Lekic Nedjeljko, University of Montenegro, Montenegro 
Liu Yu-Sian, National Chiao Tung University, Taiwan

Luciano Agostini, Universidade Federal de Pelotas, Brazil

Luis Cruz, Instituto de Telecomunicações - Coimbra, Portugal

Lukasz Kulas, Gdańsk University of Technology, Poland

\section{M}

M. Slanina, Brno University of Technology, Czech Republic Mabed Hakim, University of Franche-Comté, France

Maglaras Athanasios, Technological Educational Institute of Larissa, Greece

Majda Petric, University of Belgrade, Serbia

Maksim Shudrak, Siberian State Aerospace University, Russia

Malyutin Alexandr, JSC "Concern "Sozvezdie", Russia

Manuel Graña, ENGINE centre, Wroclaw University of Technology, Poland

Manuel Vázquez, ICMM-CSIC, Spain

Marcos Faundez-Zanuy, TecnoCampus, Spain

Marcus Svoboda, Politehnica University of Timisoara, Romania

María Botón-Fernández, Ciemat, Spain

María Julia Fernández-Getino, Charles III University of Madrid, Spain

Maria-Alexandra Paun, University of Cambridge, United Kingdom

Mario Cifrek, University of Zagreb, Croatia

Mario Alvarado, MINES ParisTech, France

Marjan Gusev, Faculty of Natural Science and Mathematics, Macedonia

Marta Pla-Castells, Universitat de Valencia, Spain

Marthinus Booysen, Stellenbosch University, South Africa

Matthias Sauppe, Technische Universität Chemnitz, Germany

Matthias Wolff, Brandenburg University of Technology,

Germany

Maxim Dybko, Novosibirsk State Technical University, Russia

Michaelk. Bourdoulis, University of Patras, Greece

Michele Albano, CISTER/ISEP, Polytechnic Institute of Porto, Portugal

Miguel Angel Guevara, University of Aveiro, Portugal

Mihail Antchev, Technical University - Sofia, Bulgaria

Mihail Gaianu, West University of Timișoara, Romania

Mile Jovanov, Faculty of Natural Science and Mathematics,

Skopje, Macedonia

Milica Pejanovic-Djurisic, University of Montenegro,

Montenegro

Milos Oravec, Slovak University of Technology Bratislava, Slovakia

Milos Borenovic, University of Westminster, United Kingdom

Minas Dasygenis, University of Western Macedonia, Greece

Mirko Palazzo, ABB Switzerland, Switzerland

Mohammad Hasan, University of North Carolina at Charlotte,

USA

\section{$\mathbf{N}$}

Najeeb Ullah, Politecnico Di Torino, Italy

Nariman Rahmanov, CPEE, Azerbaijan
Nasir Faruk, University of Ilorin, Nigeria

Nasrullah Armi, Indonesian Institute of Sciences, Indonesia

Natasa Neskovic, University of Belgrade, Serbia

Nevena Ackovska, "Sts. Cyril and Methodius" University, Macedonia

Nikola Vištica, HERA, Croatia

Nora Barroso, University of the Basque Country, Spain

\section{0}

Ognjen Kuljaca, Brodarski institut, Croatia

Olaf Winne, Lamtec / Universität Rostock, Germany

Oliver Jokisch, Leipzig University of Telecommunication, Germany

Owen Casha, University of Malta, Malta

\section{$\mathbf{P}$}

Padma lyenghar, University of Osnabrueck, Germany

Paul Micallef, University of Malta, Malta

Paweł Ksieniewicz, Wroclaw University of Technology, Poland

Pedro Valero, BCAM, Spain

Pedro A. Amado Assuncao, Portugal

Peter Glosekotter, University of Munster, Germany

Petre - Marian Nicolae, University of Craiova, Romania

Pilar Calvo, University of the Basque Country, Spain

Poleš Damir, Croatia Control, Croatia

Premek Brada, University of West Bohemia, Czech Republic

\section{$\mathbf{R}$}

Radonjic Milutin, University of Montenegro, Montenegro Raman Ramsin, Sharif University of Technology, Iran Reuben A. Farrugia, University of Malta, Malta Reza Malekian, University of Pretoria, South Africa Riaan Stopforth, University of KwaZulu-Natal, South Africa Richard Lipka, University of West Bohemia, Czech Republic Roberto Alvaro-Hermana, UPM, Spain

Roberto Dominguez, University of Seville, Spain

Roc Berenguer, CEIT, Spain

Roger Achkar, AUST, Lebanon

Rosa Guadalupe Gonzalez, Pontificia Universidad Católica de Valparaiso, Chile

Ruth Leao, Universidade Federal do Ceará, Brazil

Ruxandra Mihaela Botez, École de Technologie Supérieure, Canada

\section{$S$}

Samia Loucif, ALHOSN University, United Arab Emirates Salvatore Cannella, University of Seville, Spain

Sameer Alawnah, American University of Sharjah, United Arab Emirates

Sandhya Pattanayak, Narula institute of technology, India Sandra Castaño, Universidad Carlos III de Madrid, Spain

Sarunas Paulikas, Vilnius Gediminas Technical University, Lithuania 
Sasko Ristov, Faculty of Natural Sciences and Mathematic Skopje, Macedonia

Seniha Ketenci, Karadeniz Technical University, Turkey

Sergeyv. Brovanov, Yandex, Russia

Sergio Bernabe, University of Extremadura, Spain

Sergio Sanchez, University of Extremadura, Spain

Serkan Bahceci, Meliksah University, Turkey

Slavko Krajcar, University of Zagreb, Croatia

Slobodan Lukovic, University of Lugano, Switzerland

Soraya Kouadri, The British Open University, United Kingdom

Sorin Musuroi, Politehnica University of Timisoara, Romania

Spiros Louvros, Alexander Technological Educational Institute

of Thessaloniki, Greece

Srete Nikolovski, University of Osijek, Croatia

Stanislav Racek, University of West Bohemia in Pilsen, Czech

Republic

Stelios Papadakis, TEl Kavalas, Greece

Stjepan Sučić, Končar-KET, Croatia

\section{T}

Teodor Lucian Grigorie, University of Craiova, Romania

Teresa Serrano, CSIC, Spain

Tetiana Kot, NTUU "KPI", Ukraine

Tomas Potuzak, University of West Bohemia, Czech Republic

Tomislav Plavsic, HEP TSO, Croatia

Tze-Yee Ho, Feng Chia Univ., Taiwan

\section{U}

Uduak Ekpenyong, University of Pretoria, South Africa
V. Kaburlasos, TEl of Kavala, Greece

Victorino Franco, Universidad de Sevilla, Spain

Valentin Savin, CEA-LETI, France

Vancea Florin, University of Oradea, Romania

Vasa Radonic, Faculty of Technical Science, Serbia

Vassilis Fotopoulos, Hellenic Open University, Greece

Veselin Ivanovic, Faculty of Electrical Engineering Podgorica,

Montenegro

Vesna Crnojevic-Bengin, University of Novi Sad, Serbia

Vicente R. Tomás, U. Jaume I, Spain

Víctor Gil, Charles III University of Madrid, Spain

Vitaly Levashenko, University of Zilina, Slovakia

Vladimir Milovanovic, Vienna University of Technology, Austria

Vladimir Katic, University of Novi Sad, Serbia

Vlastimir Glamocanin, Faculty of Natural Science and Mathematics, Skopje, Macedonia

Vyacheslav Zolotarev, Siberian State Aerospace University, Russia

\section{$\mathbf{X}$}

Xenofon Fafoutis, Technical University of Denmark, United Kingdom

\section{$\mathbf{Y}$}

Yury B. Nechaev, JSC «Sozvezdie» Concern», Russia

\section{Z}

Željka Lučev, University of Zagreb, Croatia

Zhe Chen, Aalborg University, Denmark 


\section{Table of Contents}

Welcome

Committees.

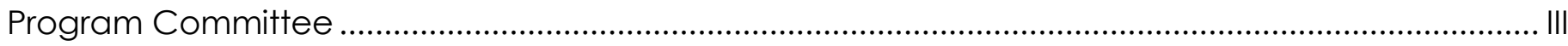

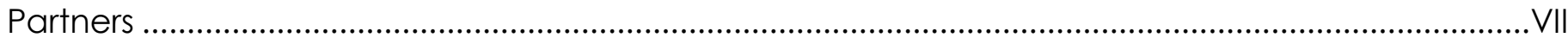

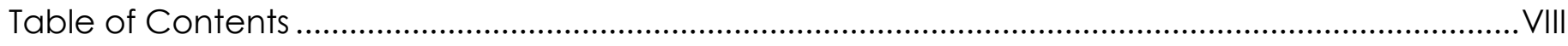

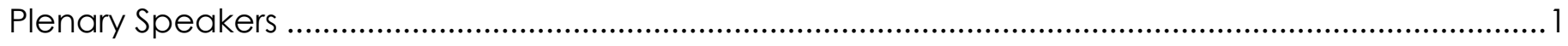

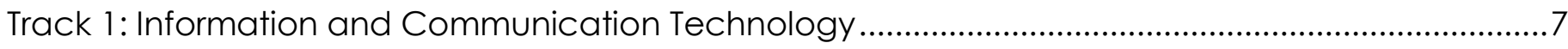

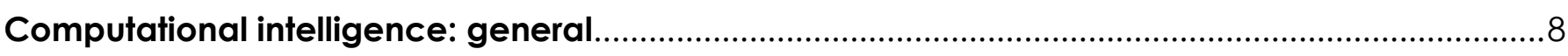

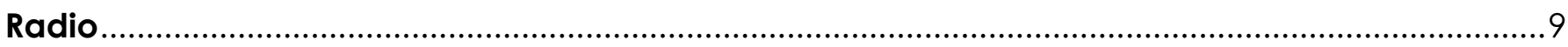

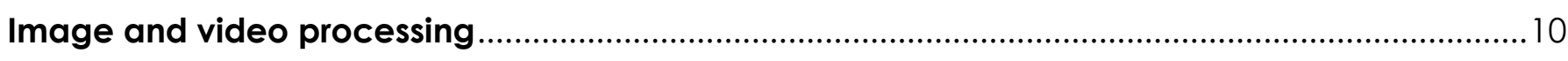

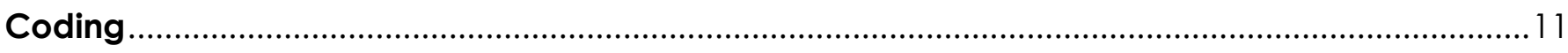

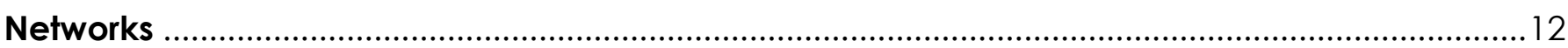

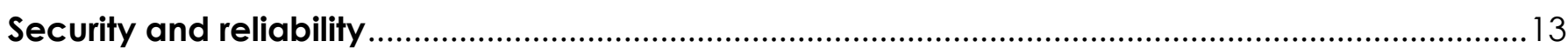

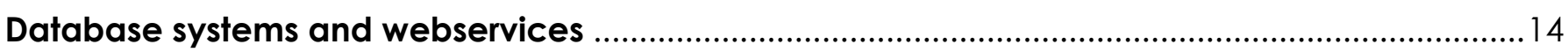

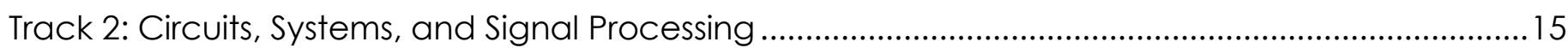

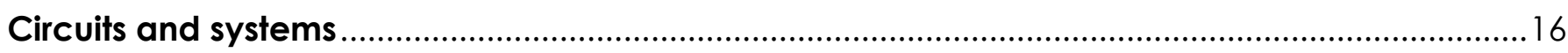

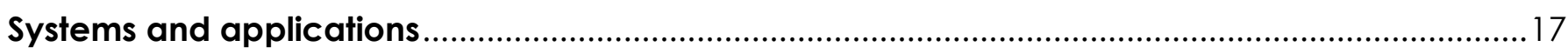

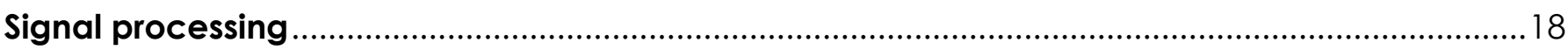

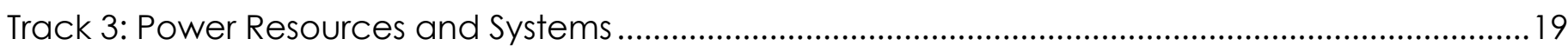

Electric vehicle, active demand control and distributed storage ................................................20

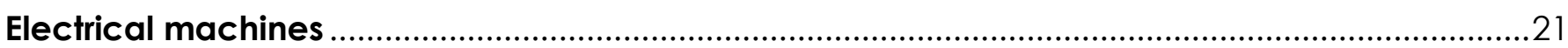

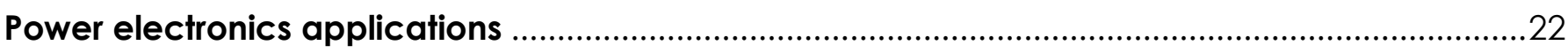

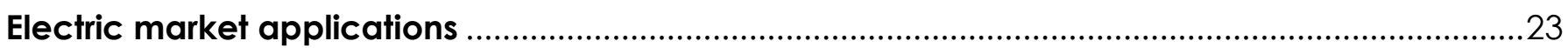

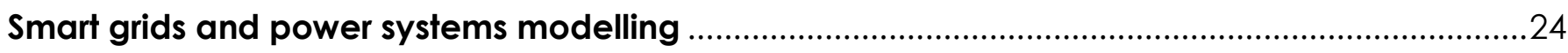

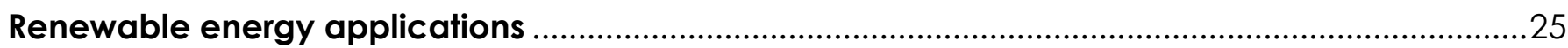

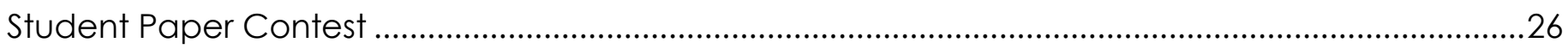

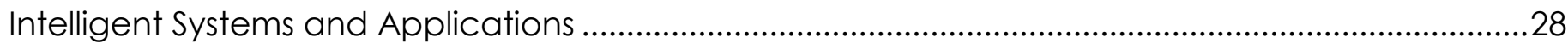

Computer: Tool for Signal/Image/Video Processing and Intelligent Systems....................................30

Image and Signal Processing for High Performance Computing environments .............................32

Workshop on Magnetic Materials for Energy Applications …............................................................34

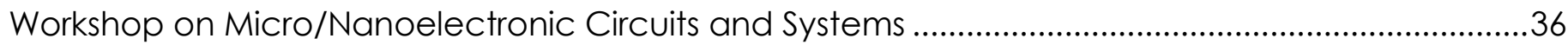

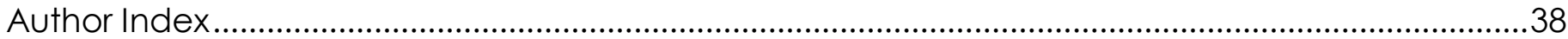


Track 3: Power Resources and Systems

Chair:

Jesús Fraile-Ardanuy 
Session 03

\section{Power electronics applications}

Primary Control Operation Modes in Islanded Hybrid ac/dc Microgrids

Eneko Unamuno and Jon Andoni Barrena.

Small Signal Assessment of an AC System Integrated with a VSC-HVDC Network

Duc Nguyen Huu.

Adaptive Coordinated Droop Control for Multi-Battery Storage

Duc Nguyen Huu and Hung Truong Nam.

An Ultra-Low-Power Boost Converter for Micro-Scale Energy Scavenging

Harmonic and Imbalance Voltage Mitigation in Smart Grids: A DSTATCOM Based Solution 507

Pedro Roncero-Sanchez and Enrique Acha.

Control and Stability Analysis of Interfaced Converter in Distributed Generation Technology

E. Pouresmaeil, M. Mehrasa, M.A. Shokridehaki, E.M.G. Rodrigues, J.P.S. Catalão.

Direct Phase Digital Control Method in Power Inverters Based on Dumping Frequency Analysis

Ljupco Karadzinov and Goce Stefanov. 